\title{
Immunologic and Cellular Changes
}

\section{Accompanying the Therapy of Pollen Allergy}

\author{
D. A. Levy, L. M. Lichtenstein, E. O. Goldstein, and K. Ishizaka \\ From the Departments of Radiological Science, Medicine, and Pediatrics of the \\ Johns Hopkins Medical Institutions, Baltimore, Maryland 21205, and The \\ Children's Asthma Research Institute and Hospital, Denver Colorado 80904
}

A B S T R A C T We had found previously that children with ragweed hay fever were somewhat less symptomatic after preseasonal immunization with large doses of ragweed pollen extract than were placebo-treated children. To study further the immunologic changes which accompany immunotherapy, these children were treated again the following year. Each patient served as his own control.

Serum blocking (IgG) antibody, measured by inhibition of antigen-induced leukocyte histamine release, was increased 20 - to 40 -fold after therapy. The anticipated postpollen season increase of serum reaginic ( $\operatorname{IgE}$ ) antibody, measured by passive sensitization of leukocytes from nonallergic donors, was suppressed. Instead, the mean titer was decreased after treatment. Total serum $\operatorname{IgE}$ levels, measured by radial radioimmunodiffusion assay, were higher than normal; were correlated with reaginic antibody titers; and also did not increase in the pollen season after treatment. The concentration of both $\operatorname{IgE}$ and reaginic antibody was lower in the older children, irrespective of treatment.

Leukocyte response to ragweed antigen $\mathrm{E}$ and guinea pig anti-IgE antiserum was assessed by means of in vitro histamine release techniques. After treatment, the leukocytes of 21 patients were less sensitive (11 cases), or less reactive (10 cases), to antigen $\mathrm{E}$. Response to anti-IgE antibody also was diminished after treatment. In four cases, neither anti-IgE nor antigen $\mathrm{E}$ induced histamine release, although both $\operatorname{IgE}$ protein and ragweed-specific IgE antibody were present in the patients' own sera.

This work was presented in part at the National Meeting of the American Federation for Clinical Research, Atlantic City, N. J., 3 May 1970. Clin. Res. 18: 428.

Dr. Lichtenstein received a U. S. Public Health Service Research Career Development Award 1 KO4-AI42373 from the National Institute of Allergy and Infectious Disease.

Received for publication 28 May 1970 and in revised form 9 October 1970.
Clinical improvement was correlated best with decreased leukocyte sensitivity and leukocyte reactivity to ragweed antigen $\mathrm{E}$. It appeared that decreased cell sensitivity was related to lower serum reaginic antibody levels. Decreased cell reactivity, in the presence of both $\operatorname{IgE}$ protein and $\operatorname{IgE}$ antibody in the serum, may indicate a change in cellular response mechanisms. These studies suggest that clinical improvement following specific immunotherapy must be the result of complex changes in the immunologic and cellular components of allergic disease.

\section{INTRODUCTION}

Immunotherapy has long been the major form of treatment for pollen allergy. In recent controlled studies, it has been shown to result in at least partial amelioration of the symptoms of hay fever in adults and children (1-4). Previous studies of the immunologic parameters of pollinosis have demonstrated that immunization with pollen allergen stimulates the production of blocking antibody $(5,6)$, reduces the serum titer of reaginic antibody (7-9), and also decreases the in vitro allergen-induced release of histamine from the patients' leukocytes $(4,10,11)$.

In recent studies, reaginic antibodies, which are responsible for the sensitivity of allergic individuals to specific allergens, have been identified as IgE immunoglobulins (12). Immunoglobulins of this class are present in the serum and on the histamine-containing cells of both allergic and nonallergic individuals. The mean concentration of IgE in serum from allergic individuals was found to be several times higher than the concentration in normal serum (13-15). Likewise, the leukocytes of allergic individuals were reported to release more histamine than normal leukocytes when reacted with anti$\operatorname{IgE}$ antibody (16). 
TABLE I

Age, Antigen Dosage and Symptom Indexes of the Two Patient Groups

\begin{tabular}{|c|c|c|c|c|c|c|c|}
\hline \multirow[b]{3}{*}{ Group } & \multirow{3}{*}{$\begin{array}{c}\text { No. of } \\
\text { patients }\end{array}$} & \multirow[b]{3}{*}{ Age } & \multirow{2}{*}{\multicolumn{2}{|c|}{ Total antigen dose (PNU*) }} & \multicolumn{3}{|c|}{ Symptom index } \\
\hline & & & & & & & Difference \\
\hline & & & Average & Range & 1967 & 1968 & $(1967-68)$ \\
\hline & & yr/month & & & & & \\
\hline I & 10 & $12 / 8$ & 27,039 & $12,050-38,150$ & $\begin{array}{c}0.400 \\
\pm 0.038(\mathrm{sE})\end{array}$ & $\begin{array}{r}0.149 \\
\pm 0.044\end{array}$ & $\begin{array}{l}+0.251 \\
\pm 0.059\end{array}$ \\
\hline II & 14 & $13 / 4$ & 28,755 & $5,200-39,650$ & $\begin{array}{r}0.182 \\
\pm 0.041\end{array}$ & $\begin{array}{r}0.170 \\
\pm 0.055\end{array}$ & $\begin{array}{l}+0.012 \\
\pm 0.028\end{array}$ \\
\hline
\end{tabular}

* PNU, protein nitrogen units; 1 PNU, $0.01 \mu \mathrm{g}$ protein N. In 1967, group I received placebo therapy and group II received an average of 22,000 PNU of WRE.

The precise relationship between these laboratory parameters and the course of pollen allergy still is not known. In order to explore this problem further, measurements of the serum $\operatorname{IgE}$ concentration and the response of leukocytes to anti-IgE antibody were applied in a continuing clinical and laboratory study of ragweed hay fever in children. The results suggest that clinical improvement following immunotherapy must be the consequence of complex changes in the immunologic and cellular components of allergy.

\section{METHODS}

Patients. 35 school aged children had entered this study in 1966. All the children had a well documented history of ragweed hay fever for at least $2 \mathrm{yr}$ prior to that time, with symptoms which were inadequately controlled by antihistaminic drugs. Each child had a positive direct skin test reaction to whole ragweed extract (WRE) ${ }^{1}$ and to ragweed antigen $\mathrm{E}$ (17). In addition, greater than $70 \%$ of the total cellular histamine was released from the patients' leukocytes after reaction in vitro with ragweed antigen (4). No patient had received immunotherapy prior to entering the study. Their level of clinical and laboratory sensitivity to ragweed pollen was not significantly different from that of adult patients with ragweed hay fever previously studied (6). 18 of these 35 children had received biweekly injections of WRE from April through August 1967 up to a maximum of 3500 protein nitrogen units $(1 \mathrm{PNU}=0.01 \mu \mathrm{g}$ of protein nitrogen) per injection. The median cumulative preseasonal WRE dose was 22,000 PNU (range 10,000-31,000 PNU). The remaining 17 children received placebo injections containing $0.01 \mathrm{PNU}$ per $\mathrm{ml}$ of the same extract.

24 of these children returned for treatment in early 1968 , and they constitute the present study groups (Table I). The 1st yr treatment group (I) consisted of 10 patients who had received placebo therapy in 1967, and the 2 nd $\mathrm{yr}$ treatment group (II) consisted of 14 patients who had received ragweed extract as described above. The other 11 patients ( 7 placebo treated and 4 pollen treated) did not return in 1968, either because they had sought treatment for

${ }^{1}$ Abbreviations used in this paper: WRE, whole ragweed extract; PNU, protein nitrogen units; SI, in-season symptom index; DG, standard reaginic serum. their hay fever elsewhere or because they had moved away from Baltimore.

Antigens and antiserum. Aqueous whole ragweed extract (WRE) administered to the patients was obtained from commercial sources. We were aware of reported discrepancies between the biological activity and the protein nitrogen content of such extracts (18). Purified ragweed pollen antigen $\mathrm{E}$ used in the in vitro studies was kindly supplied by Dr. T. P. King of The Rockefeller University, and by Dr. F. C. McIntire of Abbott Laboratories. The preparation of guinea pig antiserum specific for $\operatorname{IgE}$ has been described previously (19).

Pollen counts. Daily quantitative pollen counts were obtained by means of the Intermittent Roto Slide sampler ${ }^{2}$ (20).

Symptom analysis. A special diary form that had been used in the 1st yr of this study was maintained by, each patient from 31 July to 29 September 1968. Patients rated each symptom (sneezing, stuffy and runny nose, itchy eyes, and cough) according to its duration during each $8 \mathrm{hr}$ period. Patients were provided with chlorpheniramine tablets $(4 \mathrm{mg}$ ) for symptom relief and entered the number of tablets taken on the diary. The forms were collected each week and encoded for computer analysis. The average symptom score per patient during the ragweed pollen season was calculated and used to derive an in-season symptom index (SI) for each patient by methods described in detail elsewhere (21). An SI per day for each group of patients was calculated by the same method.

Laboratory studies. A venous blood sample was obtained prior to initiation of therapy and at bimonthly intervals thereafter. Leukocyte histamine release studies with ragweed antigen $\mathrm{E}$ and with guinea pig anti-IgE were done on the day of bleeding, using techniques previously described $(4,16,22)$. The leukocyte response is characterized in two ways: the maximum amount of histamine release obtainable with any amount of antigen or antiserum is referred to as cell reactivity, and the concentration of antigen or antiserum required to release $50 \%$ of the cellular histamine is referred to as cell sensitivity. Serum was separated the same day and stored at $-20^{\circ}$ without loss of antibody activity (23). Reaginic antibody and blocking antibody titers were measured with leukocyte histamine release methods described in detail elsewhere $(23,24)$. The reaginic antibody titer $\left(\mathrm{PLS}_{\mathrm{b}_{0}}\right)$ is defined as the reciprocal of the dilu-

\footnotetext{
${ }^{2}$ We are grateful to Mr. Frank Ward for furnishing the pollen counts.
} 


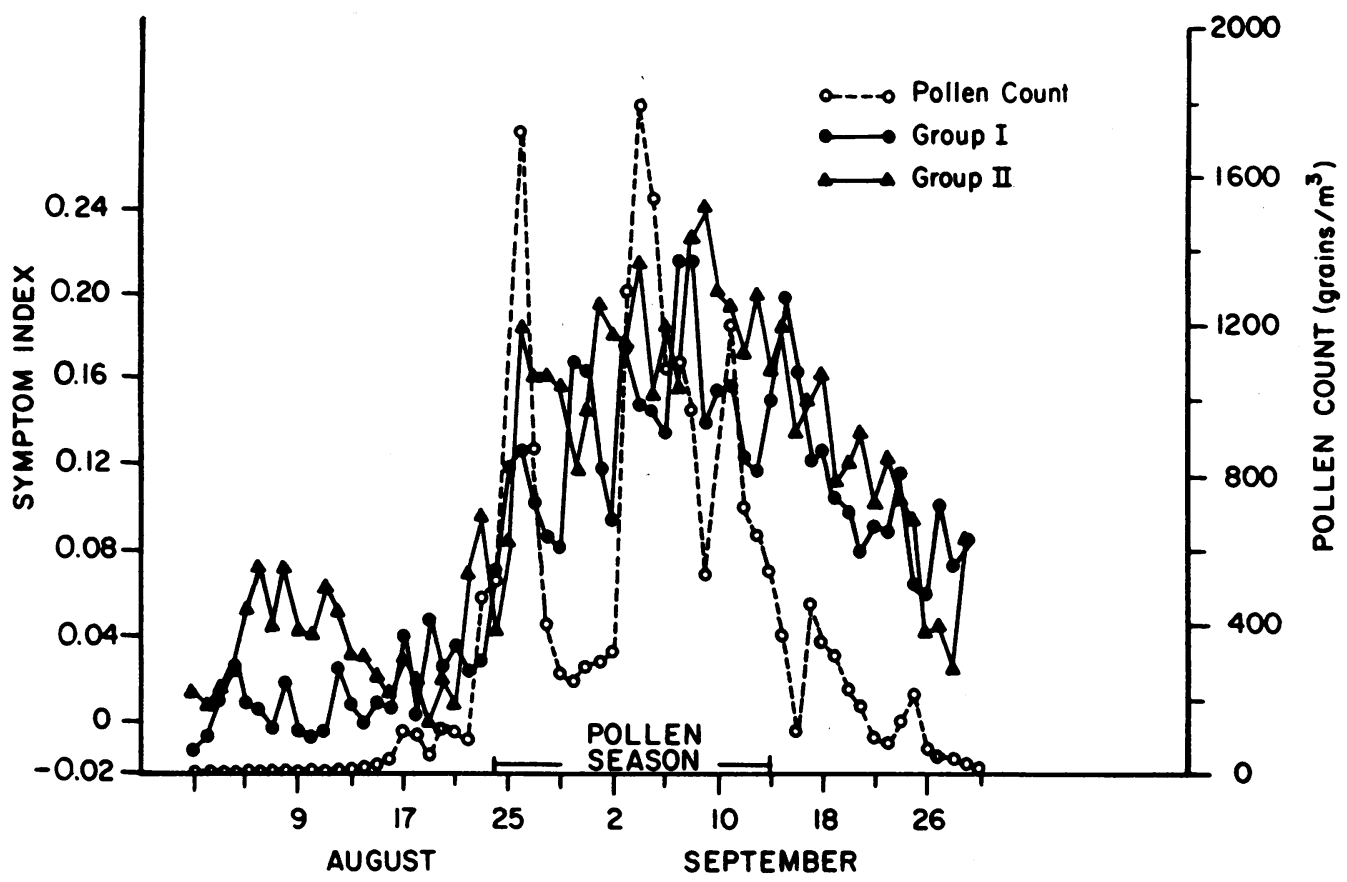

FIGURE 1 Comparison between average symptom index of two groups of patients and quantitative pollen counts. Group I, 1st yr treatment group; group II, 2nd yr treatment group.

tion of allergic serum required for passive sensitization of a standardized set of normal leukocytes to release $50 \%$ of their histamine in response to antigenic challenge (23). In the present study, each patient's 1968 serum samples were assayed in one experiment, together with a sample obtained in the fall of 1967 , and a standard reaginic serum (DG). The patient's serum titers then were normalized with the titer of the standard serum. The blocking antibody titer is the reciprocal of the dilution at which the test serum inhibits antigen-induced leukocyte histamine release by $50 \%$. Serum IgE concentrations were determined with a radial radioimmunodiffusion assay method (25).

\section{RESULTS}

The first year of this study demonstrated a highly significant clinical difference between the treated and control groups (4). Several immunologic parameters showed a moderate degree of correlation with the clinical change, and in order to maximize our opportunity to observe these correlations, we elected to treat all of the children who returned for a 2nd yr of observation. Accordingly, beginning on 29 March 1968, all patients were given subcutaneous injections of WRE twice a week. Doses were increased stepwise from 1 PNU until treatment was discontinued on August 6, 1968. The maximum single dose attained was 4000 PNU. Most patients tolerated this dose without difficulty. In 3 cases, however, the injection of 1000,1500 , and 2500 PNU, respectively, caused a mild generalized allergic reaction. Larger doses were not given to these three patients. Table I lists the average cumulative doses attained in the preseasonal period. They ranged from $5200-39,650$ PNU. The mean cumulative doses for the 1 st $\mathrm{yr}$ and $2 \mathrm{nd} \mathrm{yr}$ treatment groups were essentially equal and they exceeded by $27 \%$ the mean dose given to the patients treated in 1967.

Fig. 1 shows that ragweed pollen was detected in 1968, from August 14th to September 30th, with maximum densities on August 26th and September 4th. We arbitrarily define the pollen season as the period when daily counts exceed 500 grains $/ \mathrm{m}^{3}$ of air. In 1968, the ragweed pollen season began on August 22nd, and ended on September 14th. The 1968 season was more intense than the 1967 season as judged both by daily pollen counts and by the symptom scores of untreated adult patients. ${ }^{3}$ Fig. 1 also shows the average daily SI for both treatment groups. As in previous studies, maximum symptoms occurred during the peak of the pollen season. There was no difference between the daily SI of the two groups. The higher daily SI in the 2nd yr treatment group during the $2 \mathrm{nd}$ wk of August was due to the occurrence in one patient of conjunctival inflammation and cough from an apparently nonallergic acute illness.

Table I lists the average seasonal SI for both groups of patients in 1967 and 1968. The SI in 1967 served as the basis on which we assessed the effectiveness of treatment administered in 1968. Most patients in the 1st yr

\footnotetext{
${ }^{3}$ Norman, P. S. Personal communication.
} 
treatment group had fewer symptoms in 1968; the average decrease in their SI was 0.251 , which is significant at the $1 \%$ level. However, in the present study a second course of therapy was not followed by further improvement, as indicated by a mean SI decrement of only 0.012 . Many patients still had mild to moderate symptoms during the period of peak pollen density.

That WRE was antigenic in these patients was confirmed by measurement of serum blocking antibody titers. Fig. 2 shows that all patients treated in 1967 experienced a rise in titer whereas the titer did not change in the placebo group. In 1968, all patients were given WRE and all had higher titers after the course of injections. Although the mean titer (284) after a second course was slightly higher than after a first course (161), the difference between the mean titers is not statistically significant by the Wilcoxon test. In neither year was there a significant correlation between these antibody levels and the relative degree of symptom relief, as judged by the SI differences listed in Table I.

Fig. 3 shows changes in the reaginic antibody titers in the two treatment groups. In 1967, the mean titer increased after the pollen season $70 \%$ in untreated (I) patients but only $23 \%$ in treated (II) patients (4). Over the next 5 months, the titer fell about 2-fold in both groups. Then, in the spring of 1968, the initiation of treatment in the previously untreated children (I) caused a 2 -fold rise in the reagin level. This increase was not sustained; after May, the titer again declined. In contrast, when therapy was started in group II patients, the mean titer did not change in the following 2 months.

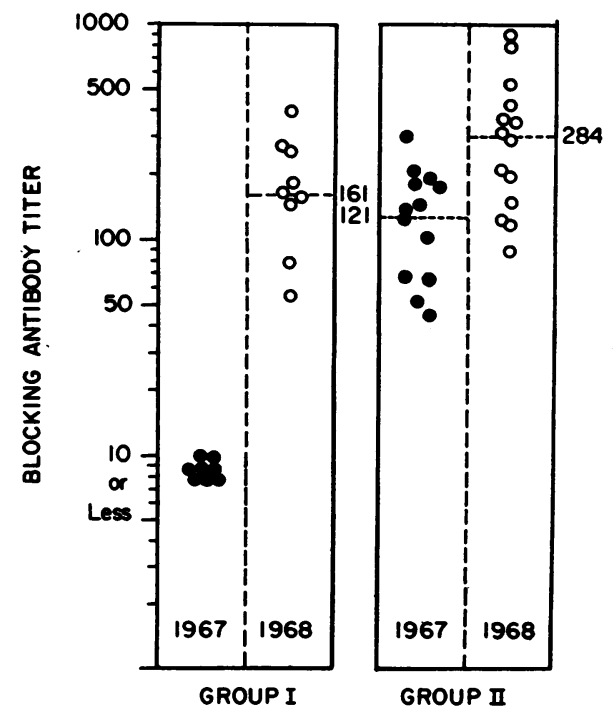

FIGURE 2 Blocking antibody levels in September 1967 (•) and September $1968(\mathrm{O})$. Each circle represents one patient; the dashed lines indicate the group average. Group I. 1st yr treatment group; group II, 2nd yr treatment group.

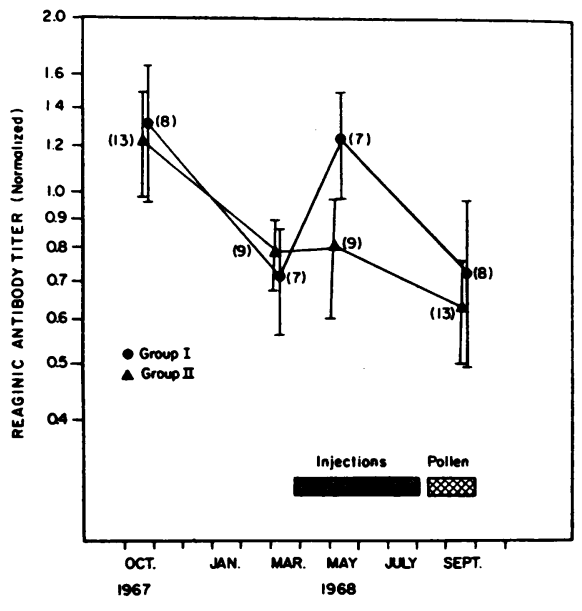

FIgURE 3 The change in reaginic antibody titer in relation to therapeutic immunization and the ragweed pollen season. Group I, 1st yr treatment group; group II, 2nd yr treatment group.

Actually, the reagin titers rose in two, fell in three and was unchanged in the remaining four of the nine patients from whom data was available. In neither group of patients did the reagin titer increase in September, after exposure to environmental pollen, as had been observed in some untreated ragweed sensitive children and adults $(4,26)$. The mean titers after each course of treatment were about 2 -fold lower than they were in the same month of the preceding year, a difference which is statistically significant $(P<0.01)$ by the Wilcoxon test.

We will show that the reagin titer can be related to the sensitivity of leukocytes to antigen, which in turn has been related to the level of symptoms $(3,6)$. However, we could not demonstrate a statistically significant relationship between reagin titer and SI, possibly because symptom scores were correlated only roughly at best with the other laboratory parameters. Of the 24 patients in the present series, the two with the highest reagin titer in September, 1968 had the 3rd and the 17th highest symptom indexes, respectively, whereas the two patients with the lowest titers had the 19th and the 4th highest SIs. Furthermore, there was no correlation between the amount of change in serum reagin titer and the relative degree of symptom relief. Even though reagin levels continued to decrease in the 2nd yr of treatment at the same rate as in the first, significant clinical improvement apparently did not occur after the second course of immunotherapy.

In Fig. 4, reaginic antibody titers in September, 1968 are plotted as a function of each child's age. A significant inverse relationship is apparent $(P<0.001)$. Leukocyte sensitizing activity was present in serum from all these children, and the highest titers were found in the sera of the younger patients. In contrast, sera from half 


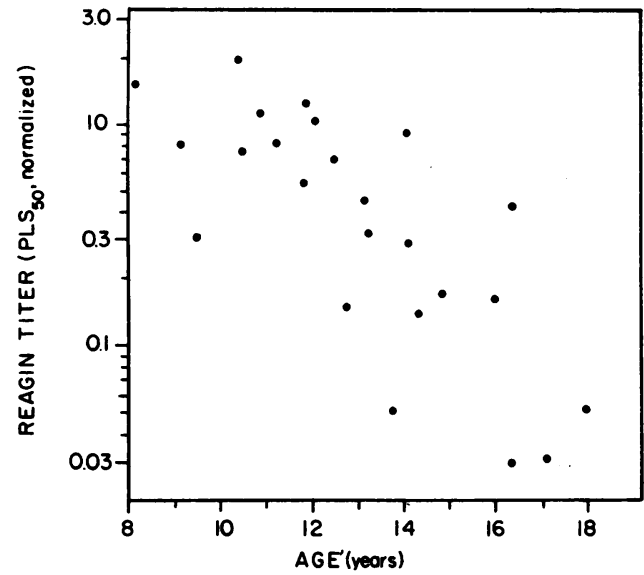

FIgURE 4 The relation between reaginic antibody titer and the age of ragweed-sensitive children. Correlation coefficient $r=0.74 ; P<0.001$.

of a group of 44 adult patients, whose leukocytes were as sensitive to ragweed antigen as were those of the children, had insufficient reaginic antibody for measurement by leukocyte sensitization."

As described by Berg and Johansson (14), the mean IgE concentration rises slowly throughout childhood. From 6.5 to $15.5 \mathrm{yr}$, the mean concentration increases from $251 \pm 167$ to $330 \pm 212 \mathrm{ng}$ per ml. Fig. 5 shows the $\operatorname{IgE}$ concentration in the serum of 22 ragweedsensitive children in July, 1968 in comparison with the concentration range found in normal children. The concentration in our patients' sera ranged from 160 to $4290 \mathrm{ng} / \mathrm{ml}$ and the mean, $1045 \mathrm{ng} / \mathrm{ml}$, was about 3 times greater than the mean in normal serum. The mean concentration in serum obtained in October was 963 $\mathrm{ng} / \mathrm{ml}$, suggesting that total serum $\operatorname{IgE}$ was not increased as a result of the seasonal exposure to pollen in these treated children. In contrast to the trend in normal children, the $\operatorname{IgE}$ level was inversely related to age ( $P$ $<0.001)$. The data were similar to those for reagin (Fig. 4) and, as shown in Fig. 6, the total IgE concentration was correlated $(P<0.01)$ with the titer of antigen $E$-specific reagin in the serum. In spite of the presence of higher levels of serum $\mathrm{IgE}$ antibody, the younger children did not have greater clinical sensitivity to ragweed pollen as judged by their symptom indexes.

Prior to the initiation of therapy in 1967, the leukocytes of all the patients had released more than $70 \%$ of their total histamine when reacted with ragweed antigen. In the period from early 1967 to the fall of 1967, the leukocytes of untreated patients became, on the average, more sensitive to ragweed antigen, i.e. required less antigen to release $50 \%$ histamine, while the leukocytes of treated patients tended to become less

${ }^{4}$ Levy, D. A. Unpublished observation. sensitive to ragweed antigen, i.e. required more antigen to release $50 \%$ histamine. Additionally, the cells of one-third of the treated patients became significantly less reactive in that the maximum amount of histamine they released was less than $50 \%$ (4). Fig. 7 shows the changes that occurred between the fall of 1967 and the fall of 1968. The cells of all 10 patients first treated in 1968 became less sensitive to antigen $E$. In seven instances, they also released less than their previous maximum amount of histamine; and cells of two patients became virtually unreactive. Changes after a second course of treatment were not so consistent. There were five patients whose cell reactivity did not change after therapy in 1967; two of these patients (indicated by $\dagger$ ) did have a significant decrease in reactivity following their second course of treatment. Of the six patients whose cells had become less reactive in 1967, the cells of two (indicated by $\ddagger$ ) had regained significant reactivity by early 1968, and did not change thereafter.

The level of cell sensitivity prior to initiation of therapy appears to be an index of the likelihood of a significant decrease in cell reactivity after therapy. Of seven children whose leukocytes required $1 \times 10^{-4} \mu \mathrm{g}$ or more of antigen $\mathrm{E}$ per $\mathrm{ml}$ for $50 \%$ histamine release before therapy, four became virtually unreactive after therapy. In contrast, only 1 of the 17 children whose leukocytes required less than $1 \times 10^{-4} \mu \mathrm{g}$ of antigen $\mathrm{E}$ per $\mathrm{ml}$ for $50 \%$ histamine release achieved a state of unresponsiveness. In adult patients, this difference has not been observed (27).

Previously, a rough but significant correlation was found between cell sensitivity to antigen $\mathrm{E}$ and the level of symptoms reported by patients during the subsequent ragweed pollen season $(3,6)$. Among the patients in the

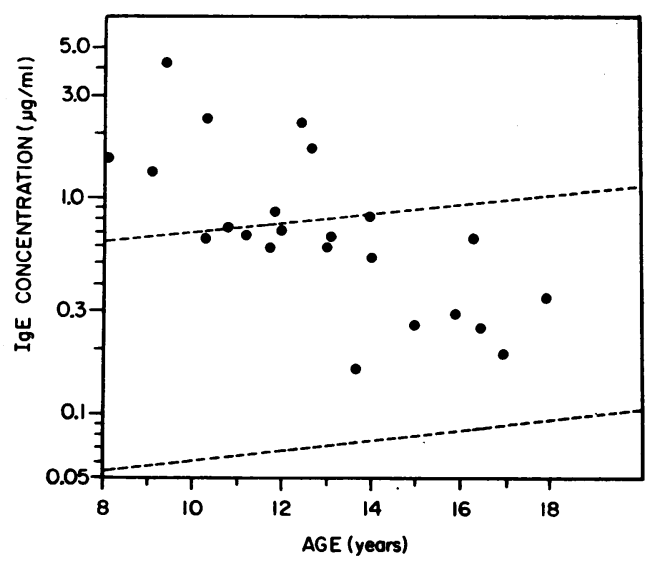

FIGURE 5 The relation between serum $\operatorname{IgE}$ concentration and the age of ragweed-sensitive children. Correlation coefficient $r=0.70 ; P<0.001$. (Normal limits $[----]$ are taken from Berg and Johansson, [see reference 15]). 
present study, those whose cells released virtually no histamine when challenged with antigen $\mathrm{E}$ in September 1967, had the lowest SIs in the 1967 pollen season (4). However, in the following year the level of cell reactivity after immunotherapy was not consistently related to the seasonal SI. For example, three patients whose cells released $10 \%$ or less of their total histamine had SIs of $0.165,0.170$, and 0.179 (mean SI for all patients in the study $=0.162$ ). Two other patients who were virtually asymptomatic $(\mathrm{SI}=0.020$ and 0.036) had cells that released 91 and 95\% histamine, respectively.

By looking at differences between measurements made in the fall of 1967 and the fall of 1968, it was possible to get a better relationship between the cell changes and changes in the patients' clinical status. Table II lists the changes in leukocyte sensitivity and/or reactivity, and the decrement in seasonal SI for all patients in the study. Each patient was ranked according to the degree of change in his cells. The lowest rank was assigned to the patient with increased cell sensitivity and the highest to the patient whose cell reactivity fell from 100 to $0 \%$ histamine release. When two patients had the same change in cell reactivity, the higher rank was given to the patient with the greater change in sensitivity. Clinical improvement in 1968 was estimated on the basis of the SI difference. The lowest rank was assigned to the patient with the least improvement (a negative difference), and the highest rank to the patient with the greatest improvement in 1968 (the largest positive difference). There was a rough, but significant, correlation between the decrease in leukocyte response and the degree of clinical improvement experienced by these children in $1968(P<0.05)$.

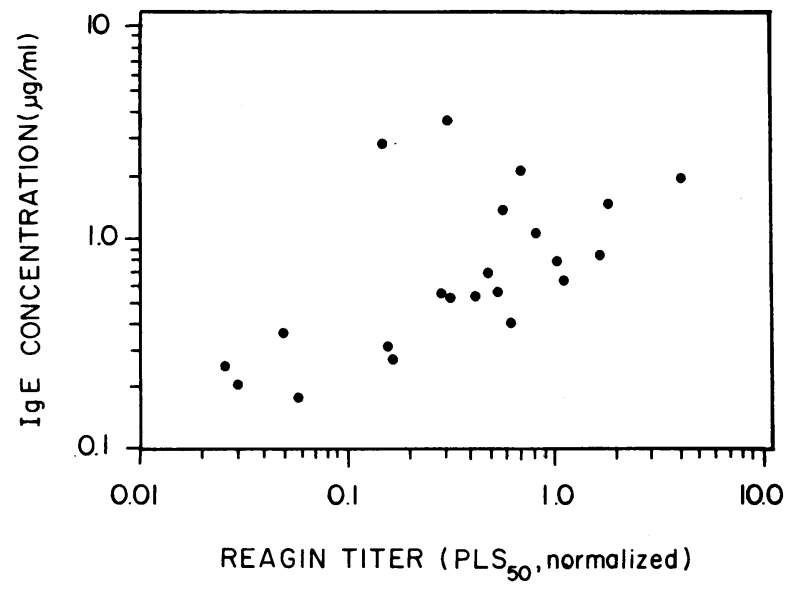

FIGURE 6 The relation between $\operatorname{IgE}$ concentration and reaginic antibody titer in the serum of ragweed-sensitive children. Correlation coefficient $r=0.61 ; P<0.01$.

It was shown previously in passive sensitization experiments that the level of cell sensitivity to ragweed antigen is a partial function of the concentration of reaginic antibody in the sensitizing medium (28). Similarly, as shown in the upper part of Fig. 8, the sensitivity to antigen $E$ of the cells of the ragweed-sensitive children in the present study varied with the concentration of reaginic antibody in their serum. Sensitivity was not estimated when maximum histamine release was less than $50 \%$. In these cases, as shown in the lower part of Fig. 8, cell reactivity is independent of the serum reagin titer. This confirms our previous report of cases in which the serum contained sufficient reaginic antibody to sensitize in vitro the cells of a normal individual even though the leukocytes of the allergic serum

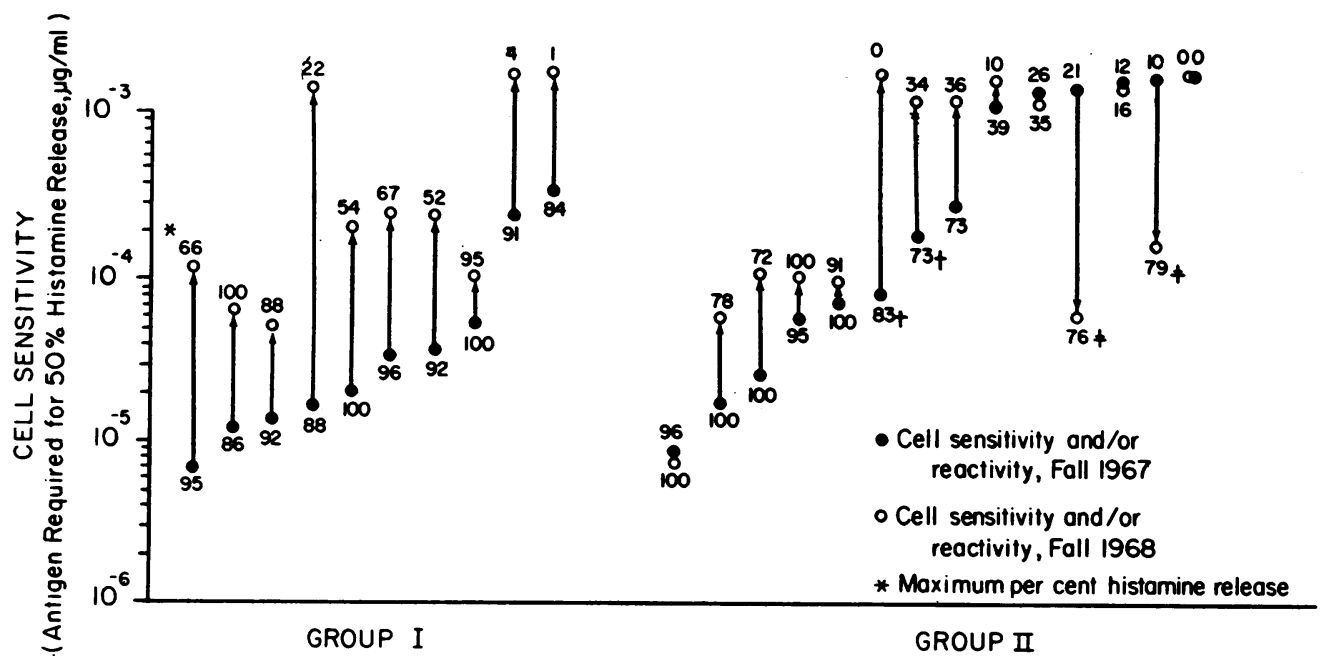

Figure 7 Compilation of changes in leukocyte responses between fall 1967 and fall 1968 . Refer to text for discussion of $\dagger$ and $\Varangle$. Group I, 1st yr treatment group; group II, 2nd yr treatment group. 
TABLE II

Correlation of Change in Leukocyte Responsiveness and the 1967-1968 Symptom Index Difference*

\begin{tabular}{|c|c|c|}
\hline Patient & WBC responseł & $\begin{array}{l}\text { Symptom } \\
\text { index } \\
\text { difference }\end{array}$ \\
\hline $\mathrm{NaSh}$ & $1.5 \times \uparrow$ sensit. & -0.038 \\
\hline TiDa & $1.4 \times \uparrow$ sensit. & +0.011 \\
\hline $\mathrm{LaPa}$ & $10 \% \rightarrow 79 \% \mathrm{HR}$ & +0.177 \\
\hline $\mathrm{DaWe}$ & $50 \% \rightarrow 76 \% \mathrm{HR}$ & -0.232 \\
\hline $\mathrm{DaBe}$ & $\rightarrow 35 \% \mathrm{HR}$ & +0.122 \\
\hline СуAu & $6 \% \rightarrow 16 \% \mathrm{HR}$ & -0.112 \\
\hline $\mathrm{ChHa}$ & $0 \% \quad \rightarrow 0 \% \mathrm{HR}$ & -0.065 \\
\hline $\mathrm{ChSa}$ & $1.3 \times \downarrow$ sensit. & +0.150 \\
\hline $\mathrm{KaCr}$ & $1.7 \times \downarrow$ sensit. & -0.021 \\
\hline ChNo & $1.9 \times \downarrow$ sensit. & +0.228 \\
\hline JuSe & $2.5 \times \downarrow$ sensit. & +0.060 \\
\hline AnJo & $2.9 \times \downarrow$ sensit. & +0.157 \\
\hline $\mathrm{GrFr}$ & $3.5 \times \downarrow$ sensit. & +0.088 \\
\hline $\mathrm{ShBu}$ & $4.0 \times \downarrow$ sensit. & -0.062 \\
\hline JoSp & $40 \% \quad \rightarrow 10 \% \mathrm{HR}$ & +0.102 \\
\hline JoLa & $5.3 \times \downarrow$ sensit. & +0.391 \\
\hline $\mathrm{ShCa}$ & $7.0 \times \downarrow$ sensit. & +0.326 \\
\hline DaTy & $7.6 \times \downarrow$ sensit. & +0.261 \\
\hline GeSa & $11 \times \downarrow$ sensit. & -0.163 \\
\hline MiJa & $25 \times \downarrow$ sensit. & +0.359 \\
\hline MaWo & $88 \% \times \rightarrow 22 \%$ HR & +0.335 \\
\hline ElLa & $83 \% \quad \rightarrow 0 \% \mathrm{HR}$ & +0.037 \\
\hline PrBo & $\rightarrow 0 \% \mathrm{HR}$ & +0.112 \\
\hline DiWe & $\rightarrow 0 \% \mathrm{HR}$ & +0.506 \\
\hline
\end{tabular}

* Spearman rank correlation coefficient $=0.45 ; P<0.05$. $\ddagger$ Changes in cell sensitivity, as defined in the text, are derived from the ratio between the measurements made in the fall of 1968, and in the fall of 1967 . When cell sensitivity could not be measured (see text), the maximum percentages of histamine released in the fall of 1967, and in the fall of 1968 are given.

donor failed to respond to specific antigen (4). The ability of such serum to sensitize cells of normal donors tends to rule out the possibility of a serum-borne inhibitor of leukocyte histamine release.

The children's leukocytes also were reacted with antiIgE serum before and after the 1968 pollen season at the same time that they were reacted with ragweed antigen. Table III lists the maximum percent histamine release obtained on both occasions with each reagent. A highly significant correlation $(P<0.001)$ obtained between the reactivity to antigen $E$ and anti-IgE antibody in July and again in October. Note particularly that in midsummer the cells of one individual released no histamine with either reagent, and in the fall, the cells from three more individuals were similarly unreactive. Thus, as some patients' cells became less reactive in the direct antigen-induced reaction, they also became less reactive in the reversed type, antiimmunoglobulin-induced response.

Since there appeared to be a quantitative relationship between the reaginic antibody in serum and that on the leukocytes of an allergic individual (the latter being reflected by the cell sensitivity to antigen), we suspected that the cell response to anti-IgE might be related to the serum IgE level. Only a few patients' cells released sufficient histamine to determine sensitivity to anti-IgE. If instead we considered cell reactivity, it was apparent that when serum $\operatorname{IgE}$ concentration was highest, the cells usually released. more histamine when challenged with anti-IgE (Table IV). This relationship is significant at the $1 \%$ level. Note also that, as was the case with reaginic antibody, there were individuals whose cells were virtually unreactive when challenged with anti-IgE even though they had normal to elevated serum IgE levels.

\section{DISCUSSION}

The primary aim of this study was to explore further the mechanisms by which immunotherapy for pollinosis brings about symptom amelioration. The present data confirm and extend previous findings with respect to

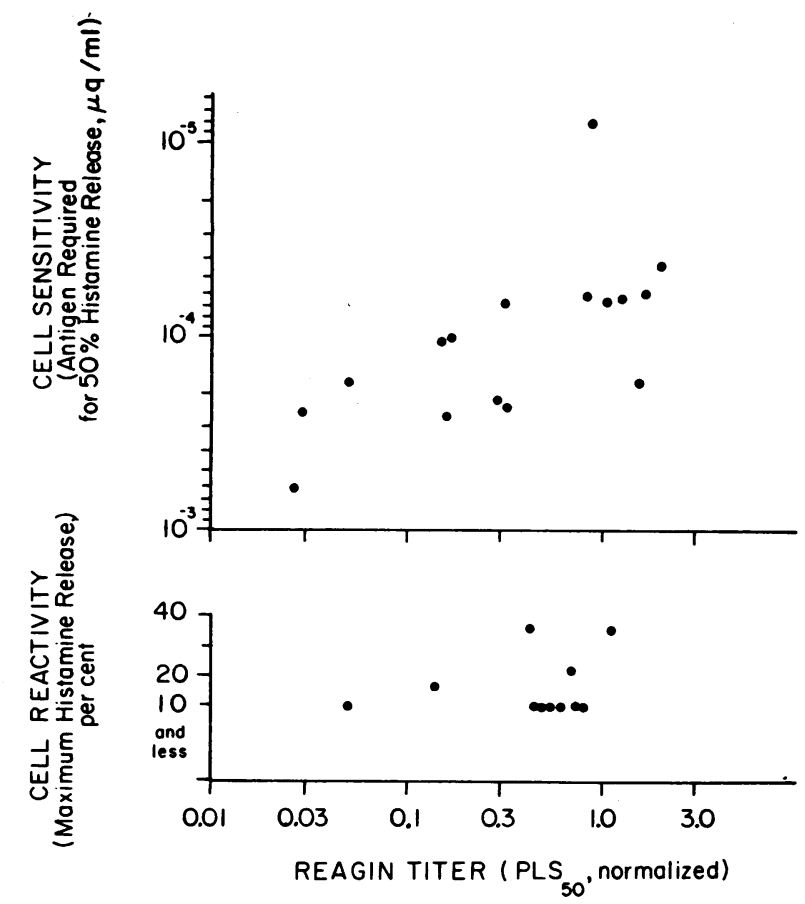

FIGURE 8 Relationships between cell sensitivity, cell reactivity and serum reaginic antibody titer in Sept. and Oct. 1968 (sensitivity, reactivity and titer are defined in the text). For cell sensitivity and reagin titer, the Spearman correlation coefficient $r_{s}=0.81 ; P<0.001$. For cell reactivity and reagin titer, $P>0.10$, 
the clinical and immunological changes which occur in allergic children as a result of specific injection therapy. More impressive changes were seen in these children than in adult hay fever patients previously studied (3, $6)$. Part of the difference may be related to the larger amount of antigen given to the children. The clinical response to immunotherapy clearly is dose dependent, and available evidence strongly suggests that relatively high dosage therapy for pollinosis is more likely to produce a favorable clinical result (2). Nonetheless, partial remission still is the rule.

Elevation of serum blocking ( $\operatorname{IgG}$ ) antibody levels occurred in all treated cases but, as in a previous study, the height of the response was not correlated convincingly with the degree of clinical improvement (6). Nonetheless, an association was apparent: treated children with raised blocking antibody titers fared better than did untreated patients with very low titers. In adults, a significant association between high blocking antibody titers and low symptom scores has been reported $(27,29)$. It seems likely that the increased production of blocking antibody induced by immunization is

TABLE III

Comparison Between Maximal Leukocyte Responses to Anti-IgE Antibody and to Ragweed Antigen $E$ in July and October $1968 \ddagger$

\begin{tabular}{|c|c|c|c|c|}
\hline \multirow[b]{2}{*}{ Patient } & \multicolumn{2}{|c|}{ July } & \multicolumn{2}{|c|}{ October } \\
\hline & Anti-IgE & Ragweed & Anti-IgE & Ragweed \\
\hline & \multicolumn{2}{|c|}{$\%$} & & \\
\hline $\mathrm{ChHa}$ & $0^{*}$ & 0 & 0 & 0 \\
\hline DiWe & - & - & 0 & 0 \\
\hline JoSp & 6 & 11 & 2 & 10 \\
\hline MaWo & 10 & 38 & - & - \\
\hline PrBo & 15 & 34 & 0 & 0 \\
\hline $\mathrm{NaSh}$ & - & - & 5 & 36 \\
\hline $\mathrm{ShBu}$ & 20 & 66 & 10 & 34 \\
\hline LaPo & 24 & 75 & 32 & 75 \\
\hline $\mathrm{DaBe}$ & 27 & 26 & 19 & 42 \\
\hline ElLa & 33 & 75 & 0 & 0 \\
\hline $\mathrm{ShCa}$ & 33 & 67 & 27 & 48 \\
\hline $\mathrm{GeSa}$ & 34 & 100 & 31 & 69 \\
\hline DaTy & - & - & 36 & 57 \\
\hline $\mathrm{DaWe}$ & 38 & 71 & 24 & 82 \\
\hline $\mathrm{MiJa}$ & - & - & 43 & 74 \\
\hline JoLa & 46 & 100 & 70 & 92 \\
\hline JuSe & 52 & 88 & 55 & 72 \\
\hline $\mathrm{ChNo}$ & 53 & 100 & 39 & 54 \\
\hline $\mathrm{ChSa}$ & - & - & 62 & 95 \\
\hline AnJo & 65 & 93 & 61 & 89 \\
\hline $\mathrm{GrFr}$ & 69 & 89 & 57 & 85 \\
\hline $\mathrm{KaCr}$ & 86 & 99 & 76 & 100 \\
\hline
\end{tabular}

* Histamine release.

† Spearman rank correlation coefficients $r_{s}$ : July, 0.83 , $P<0.001$; October, $0.94, P<0.001$.
TABLE IV

Correlation Between Maximal Leukocyte Responses to AntiIgE Antibody and Serum IgE Concentrations*

\begin{tabular}{lcc}
\hline Patient & $\begin{array}{c}\text { Response } \\
\text { to anti-IgE } \\
\text { (histamine } \\
\text { release) }\end{array}$ & $\begin{array}{c}\text { IgE Con- } \\
\text { centration }\end{array}$ \\
\hline PrBo & 0 & ng per ml \\
ElLa & 0 & 175 \\
ChHa & 0 & 390 \\
DiWe & 0 & 565 \\
JoSp & 2 & 680 \\
NaSh & 5 & 525 \\
ShBu & 10 & 200 \\
DaBe & 19 & 605 \\
DaWe & 24 & 820 \\
SnCa & 27 & 310 \\
GeSa & 31 & 500 \\
MiJa & 43 & 1500 \\
JuSe & 55 & 770 \\
GrFr & 57 & 970 \\
AnJo & 61 & 1920 \\
JoLa & 70 & 3700 \\
KrCr & 76 & 2250 \\
\hline
\end{tabular}

* Spearman rank correlation coefficient $r_{s}=0.70 ; P<0.01$.

related to the mechanism of clinical improvement. However, the manner of its involvement has not yet been clarified by knowledge of its concentration in serum.

The serum concentration of ragweed-specific $\operatorname{IgE}$ antibody changes during the course of both untreated and treated hay fever. In untreated ragweed sensitive subjects-both children and adults-serum reagin titers have been observed to increase after the onset of the ragweed pollen season (26). The serum $\operatorname{IgE}$ concentration also increases in pollen-sensitive children following the pollination season (15). Furthermore, the postseason increase in the sensitivity of the leukocytes of untreated ragweed-sensitive children is consistent with the suggestion that seasonal exposure to pollen induces a booster response of $\operatorname{IgE}$ antibody. This increase in $\operatorname{IgE}$ antibody appears to be part of a cyclical phenomenon, the autumnal increase being followed by a gradual decrease in the antibody level. A consequence of the annual seasonal booster may be that reaginic antibody levels remain high enough for clinically apparent sensitivity to persist from year to year (30).

The initial injections of pollen extract given to previously untreated patients in the early spring were followed by a short-lived increase of serum reagin concentration, as previously reported by Sherman (31). Likewise, the serum $\operatorname{IgE}$ concentration may rise in these patients (15). In previously treated patients, the initiation of a second series of injections was not fol- 
lowed by an increase in reagin titer. Subsequently, the inhalation of ragweed pollen by treated patients during August and September produced little or no rise in reagin titer or IgE level. Thus, it appears that previous immunotherapy at least partly suppresses the boosterlike effect of inhaled or injected pollen on serum IgE antibody concentration. It is known that antibody can suppress a previously established immune response (32). Thus, the apparent suppression of $\operatorname{IgE}$ antibody could be a consequence of the presence of high levels of blocking (IgG) antibody. Such antibody-mediated inhibition might occur by diverting antigen from immunocompetent cells or by reducing the number of immunocompetent cells capable of responding to a specific antigen (33).

Reagin titers were about $50 \%$ lower after both the first and second courses of immunotherapy. Recent analysis of serum from some of these children after a third course of immunotherapy has shown that titers continued to decline at the same rate. ${ }^{5}$ In adults, Sherman and Connell observed a similar rate of decline of skin-sensitizing antibody titer during the 2nd through the 4 th $\mathrm{yr}$ of treatment $(8,9)$. This continued fall in serum titer in treated patients may be related to the suppression of the booster effect of inhaled pollen antigen which was noted above.

In normal children, the total serum $\operatorname{IgE}$ concentration rises slowly toward adult values during the first and second decades (14). In contrast, in allergic children, the concentration of both total $\operatorname{IgE}$ and specific $\operatorname{IgE}$ antibody is higher in the younger children and appears to decline during the second decade, irrespective of immunotherapy. The observation that reagin titers are, on the average, higher in children than in adults with similar levels of cell sensitivity to ragweed antigen also suggests a difference with age in the antibody response to inhaled pollen. There may be a relationship in children between the trend to lower $\operatorname{IgE}$ antibody levels and the possibility of spontaneous loss of clinical sensitivity to ragweed pollen.

In any case, it might be assumed that clinical improvement in this disease could be related to a decrease in $\operatorname{IgE}$ antibody concentration. The failure to find a statistically significant correlation between changes in reagin titer and symptoms could be due to the existence of a complex relationship between $\operatorname{IgE}$ antibody in plasma and that on tissue mast cells. It has been suggested, for example, that mast cells of the respiratory tract may be sensitized by $\operatorname{IgE}$ antibody produced locally (34). Furthermore, the rate of disappearance of $\operatorname{IgE}$ fixed to mast cells, as estimated from the persistence of reactivity at passively sensitized skin sites (35), may be much longer than its rate of catabolism in plasma (36). Thus, before

${ }^{5}$ Levy, D. A. Unpublished observation. the immunologic mechanism of hay fever can be fully appreciated, more must be known about the dynamics of IgE metabolism.

As in our previous report (4), there was a significant correlation between decreased leukocyte response to antigen $\mathrm{E}$ and a decrement in SI. Comparison with the data of Lichtenstein, Norman, Winkenwerder, and Osler (6) suggested that changes in cell sensitivity of the magnitude observed here could account for the degree of symptomatic improvement experienced by the children. From studies of passive sensitization, it can be inferred that sensitivity is related to the quantity of reaginic antibody which goes on to histamine-containing cells (28). Hence, reduction of the sensitivity of cells from allergic persons after therapy probably reflects a reduction in the amount of $\mathrm{IgE}$ antibody on these cells. The decrease in serum reagin titer is consistent with this notion.

The greatest degree of improvement usually was seen in the children whose leukocytes became significantly less reactive to antigen $\mathrm{E}$, a finding which is consistent with suggestions made previously by VanArsdel and Middleton (10) and by Pruzansky and Patterson (11). In passive sensitization studies, cell reactivity is minimal when the reaginic antibody concentration in the sensitizing medium is limited (28). Therefore, both decreased cell sensitivity and reactivity occurring after therapy could be related to declining serum antibody levels. However, in some cases, not only were the cells unreactive to pollen antigen, they also were unreactive to anti- $\operatorname{IgE}$ antibody and this loss of reactivity occurred even though both ragweed-specific reaginic antibody and $\operatorname{IgE}$ immunoglobulin still were present in plasma bathing the cells in vivo (see Tables III-IV, and Fig. 8). This observation suggests to us that the reduction in reactivity after immunotherapy might be due to a change in the leukocytes which is qualitatively different from the change in sensitivity. Such a change might involve, for example, an alteration of the biochemical mechanisms of allergic histamine release (37). On the other hand. May ${ }^{8}$ has found that cell reactivity to an antigen administered therapeutically can be reduced while reactivity to an unrelated antigen is retained. Still, on the basis of our data, the possibility that immunotherapy produces an intrinsic change in cell reactivity which is not antigen-specific requires further investigation.

\section{ACKNOWLEDGMENTS}

We gratefully thank Mrs. E. F. Gehret, Jr., for preparing the computer program used in this study. We are especially grateful for the able technical assistance of Mrs. Martha Widra, Mrs. Marsha Lyons, Mrs. Ann Sobotka, and Mrs. Clara Ewart. Secretarial aid was provided by Miss Iris Ellis.

This work was supported by funds from the National Institute of Allergy and Infectious Disease Research

${ }^{6}$ May, C. D. Personal communication. 
Grants AI08104, AI08270, AI04985, and from the NIH General Research Support Grant FR 5378.

\section{REFERENCES}

1. Lowell, F. C., and W. Franklin. 1965. A double-blind study of the effectiveness and specificity of injection therapy in ragweed hay fever. N. Engl. J. Med. 273: 675.

2. Norman, P. S., W. H. Winkenwerder, and L. M. Lichtenstein. 1968. Immunotherapy of hay fever with ragweed antigen $\mathrm{E}$ : Comparisons with whole pollen extract and placebos. J. Allergy 42: 93.

3. Norman, P. S. 1969. A rational approach to desensitization. J. Allergy 44: 129.

4. Sadan, N., M. B. Rhyne, E. D. Mellits, E. O. Goldstein, D. A. Levy, and L. M. Lichtenstein. 1969. Immunotherapy of pollinosis in children: Investigation of the immunologic basis of clinical improvement. N. Engl. J. Med. 280: 623.

5. Loveless, M. H. 1940. Immunological studies of pollinosis: I. The presence of two antibodies related to the same pollen antigen in the serum of treated hay fever patients. J. Immunol. 38: 25.

6. Lichtenstein, L. M., P. S. Norman, W. L. Winkenwerder, and A. G. Osler. 1966. In vitro studies of human ragweed allergy: Changes in cellular and humoral activity associated with specific desensitization. J. Clin. Invest. 45: 1126.

7. Sherman, W. B., A. Stull, and R. A. Cooke. 1940. Serologic changes in hay fever cases treated over a period of years. J. Allergy 11: 225 .

8. Connell, J. T., and W. B. Sherman. 1964. Skin-sensitizing antibody titer III: Relationship of the skin-sensitizing antibody titer to the intracutaneous skin test, to the tolerance of injections of antigens, and to the effects of prolonged treatment with antigen. J. Allergy 35: 169.

9. Connell, J. T., and W. B. Sherman. 1969. Changes in skin-sensitizing antibody titer after injections of aqueous pollen extract. J. Allergy. 43: 22.

10. VanArsdel, P. P., Jr., and E. Middleton, Jr. 1961. The effect of hyposensitization on the in vitro histamine release by specific antigen. J. Allergy. 32: 348 .

11. Pruzansky, J. J., and R. Patterson. 1968. Immunologic changes during hyposensitization therapy. J. Amer. Med. Ass. 203: 805 .

12. Ishizaka, K., and T. Ishizaka. 1968. Human reaginic antibodies and immunoglobulin E. J. Allergy. 42: 330.

13. Johansson, S. G. O. 1967. Raised levels of a new immunoglobulin class (IgND) in asthma. Lancet. 2: 951.

14. Berg, T., and S. G. O. Johansson. 1969. Immunoglobulin levels during childhood, with special regard to $\operatorname{IgE}$. Acta. Paediat. Scand. 58: 513.

15. Berg, T., and S. G. O. Johansson. 1969. IgE concentrations in children with atopic diseases. A clinical study. Int. Arch. Allergy Appl. Immunol. 36: 219.

16. Ishizaka, T., K. Ishizaka, S. G. O. Johansson, and $\mathrm{H}$. Bennich. 1969. Histamine release from human leukocytes by anti- $\gamma \mathrm{E}$ antibodies. J. Immunol. 102: 884.

17. King, T. P., and P. S. Norman. 1962. Isolation studies of allergens from ragweed pollen. Biochemistry. 1: 709.

18. Baer, H., H. Godfrey, C. J. Maloney, P. S. Norman, and L. M. Lichtenstein. 1970. The potency and antigen E content of commercially prepared ragweed extracts. $J$. Allergy. 45 : 347.

19. Ishizaka, K., and T. Ishizaka. 1968. Reversed type allergic skin reactions by anti- $\gamma \mathrm{E}$ globulin antibodies in humans and monkeys. J. Immunol. 100: 554
20. Ogden, E. C., and G. S. Raynor. 1967. New sampler for air-borne pollen: the rotoslide. J. Allergy. 40: 1 .

21. Norman, P. S., M. B. Rhyne, and M. B. Mellits. 1966. Evaluation of agents for treatment of seasonal respiratory allergies. In Clinical Pharmacology. Vol. 2. L. Lasagna, editor. Oxford. Pergamon. pgs. 639.

22. Lichtenstein, L. M., and A. G. Osler. 1964. Studies on the mechanisms of hypersensitivity phenomena. IX. Histamine release from human leukocytes by ragweed pollen antigen. J. Exp. Med. 120: 507.

23. Levy, D. A., and A. G. Osler. 1966. Studies on the mechanisms of hypersensitivity phenomena. XIV. Passive sensitization in vitro of human leukocytes to ragweed pollen antigen. J. Immunol. 97: 203.

24. Lichtenstein, L. M., and A. G. Osler. 1966. Studies on the mechanisms of hypersensitivity phenomena. XII. An in vitro study of the reaction between ragweed pollen antigen, allergic human serum and ragweed-sensitive human leukocytes. J. Immunol. 96: 169.

25. Lichtenstein, L. M., D. A. Levy, and K. Ishizaka. 1970. In vitro reversed anaphylaxis: Characteristics of anti-IgE mediated histamine release. Immunology. 19: 831 .

26. Levy, D. A., and A. G. Osler. 1967. Studies on the mechanisms of hypersensitivity phenomena. XVI. In vitro assays of reaginic activity in human sera: Effect of therapeutic immunization on seasonal titer changes. J. Immunol. 99: 1068.

27. Lichtenstein, L. M., P. S. Norman, and W. L. Winkenwerder. 1969. Immunologic and clinical studies of a single year of immunotherapy for ragweed hay fever. J. Allergy. 43: 180. (Abstr.)

28. Osler, A. G., L. M. Lichtenstein, and D. A. Levy. 1965. Immunologic aspects of human reaginic allergy: An in vitro method and some applications. Naunyn-Schmiedebergs Arch. Pharmacol. Exp. Pathol. 250: 111.

29. Starr, M. S., and M. Weinstock. 1970. Studies in pollen allergy. III. The relationship between blocking antibody levels and symptomatic relief following hyposensitization with Allpyral in hay fever subjects. Int. Arch. Allergy Appl. Immunol. 38: 514.

30. Connell, J. T., and W. B. Sherman. 1967. Hay fever symptoms related to immunological findings. Ann. Allergy. $25: 239$.

31. Sherman, W. B. 1941. Changes in serological reactions and tissue-sensitivity in hay-fever patients during the early months of treatment. J. Immunol. 40: 289.

32. Uhr, J. W., and G. Möller. 1968. Regulatory effect of antibody on the immune response. Advan. Immunol. 8: 81.

33. Feldmann, M., and E. Diener. 1970. Antibody-mediated supression of the immune response in vitro. I. Evidence for a central effect. J. Exp. Med. 131: 247.

34. Tada, T., and $\mathrm{K}$. Ishizaka. 1970. Distribution of $\gamma \mathrm{E}$ forming cells in lymphoid tissues of the human and monkey. J. Immunol. 104: 377.

35. Fireman, P., M. Boesman, and D. Gitlin. 1967. Disappearance of intradermally administered plasma immunoglobulins and skin sensitizing antibodies. J. Allergy. 40: 304.

36. Waldmann, T. A. 1969. Disorders of immunoglobulin metabolism. N. Engl. J. Med. $281: 1170$.

37. Lichtenstein, L. M. 1969. Characteristics of leukocyte histamine release by antigen and by anti-immunoglobulin and anti-cellular antibodies. In Cellular and Humoral Mechanisms in Anaphylaxis and Allergy. H. Z. Movat, editor. S. Karger AG Basel, Switzerland. 176. 